\title{
A Propósito de Sexualidades e Culturas de Resistência: Modernidade, Identidade e Política*
}

\author{
SYLVIA GEMIGNANI GARCIA**
}

\section{Introdução}

Diante do tema proposto para discussão - culturas de resistência e homossexualidades femininas no Brasil --, este artigo se orienta para a abordagem de uma problemática geral posta pelo debate sobre culturas de resistência. Se, por um lado, tal enfoque năo possibilita a abordagem de uma experiência específica, permite, por outro, tratar de alguns problemas relativos aos modos pelos quais a sociedade moderna vem concebendo a questão da especificidade.

Como sabemos, homossexualidade, lesbianismo, feminismo, e mesmo cultura e resistência, não são nomes de coisas, mas categorias e problemas e, muito especialmente, temas candentes de uma discussão acirrada, por meio da qual diferentes pessoas e grupos lutam entre si justamente para estabelecer definições para essas palavras de significados abertos e ambíguos, que atuam como "significantes flutuantes", para usar o termo de Emesto Laclau quando descreve esse tipo de luta em torno do poder de definir significados. ${ }^{3} \mathrm{Um}$ tal entendimento desses temas remete quem os estuda a um amplo quadro de debates sobre

* Texto apresentado na conferência Homossexualidades Brasileiras em Tempos de AIDS, promovida pelo Programa de Estudos e Pesquisa em Gênero, Sexualidade e Saúde do Instituto de Medicina Social da Universidade do Estado do Rio de Janeiro.

** Pós-graduanda do Programa de Doutorado do Departamento de Sociologia da Faculdade de Filosofia, Letras e Ciências Humanas da Universidade de São Paulo.

1. E. Laclau, "A Política e os Limites da Modernidade", in H. B. de Hollanda, org., Pós-Modemismo e Política, Rio de Janeiro, Rocco, 1991, pp. 127-50. 
a modernidade contemporânea que caracteriza tanto a atual teoria social quanto as reflexões dos sujeitos sociais inevitavelmente às voltas com ele.

Assim, exponho aqui alguns dilemas do debate político-cultural contemporâneo que me inquietam há algum tempo, buscando tratar das afinidades da questão lésbica com outras específicas da sociedade contemporânea, e do conjunto delas com um grupo de questões fundamentais do pensamento social e político atual. Trato, pois, mais de problemas recorrentes em formas diversas, ou melhor, de dilemas básicos observáveis em vários desenvolvimentos paralelos, que da particularidade de uma experiencia da qual sequer consigo alcançar a especificidade, que já surge desconstruída em diversidades e desigualdades nas refłexões desenvolvidas sobre ela, seja no espaço da academia, seja no interior dos movimentos sociais. ${ }^{2}$

\section{Ambigüidades, sujeitos, conflitos}

Cultura de resistência refere-se a uma problemática política no espaço das sociabilidades, isto é, no espaço da esfera privada, concebida pela modernidade clássica como locus da liberdade individual, em oposição à esfera pública, locus do poder. Trata-se, portanto, de uma questão básica para situar a própria constituição da idéia de que a resistência cultural é possível, ou seja, que a vida privada tem uma dimensão política, ou ainda, que o poder e o conflito estão presentes em todo o social, e em algumas relações mais do que em outras, especialmente naquelas que nomeamos e utilizamos os nomes para pensar com eles e também para brigarmos entre nós. Em suma, uma problemática que se refere à politização extensiva e difusa do social, correlata à crise de representação política na esfera pública institucional.

Michel Foucaralt foi um dos que elaborou o entendimento desse fenômeno de forma mais decisiva para a discussão atual. Sinteticamente, um dos pontos fundamentais de sua Microfisica é a separação entre poder e Estado, ou melhor, entre relações de poder-saber e a esfera política institucionalizada que tem o Estado como núcleo. Foucault nega veementemente a noção do poder como uma coisa que se possui e que pode, nessa condição, se localizar em um lugar específico da estrutura social. Para ele, o poder não está no Estado ou em qualquer ponto identificável da sociedade, mas em todo lugar, como relação estratégica de sujeição. O saber-poder como tecnologia de adestramento e

2. Cf., por exemplo, M. Bielsa, "O de la No Existencia del Lesbianismo", Nosotras que Nos Queremos Tanto..., Colectivo de Feministas Lesbianas de Madrid, $n^{\circ} 4$, março de 1986. 
planejamento do corpo e produtor de individuação inscreve extensivamente o poder no tecido social, na rede de relações sociais, em qualquer uma de suas esferas. $^{3}$

O principal fenômeno que sustenta a idéia contemporânea do acontecer social como antagonismo é o advento dos movimentos sociais, para usar uma expressão bem ampla. Com os estudose debates sobre os movimentos étnicos, de gênero, lingüísticos, de vizinhança, sexuais e religiosos aprendemos, nos últimos anos, que a afirmação do social como antagonismo se faz junto - e necessariamente junto — com a afirmação de uma ambigüidade definidora desses enfrentamentos, da perspectiva dos dominados de todo tipo, de todos os assujeitados pelos poderes. Aprendemos que toda resistência é, por definição, resistência e conformismo: um modo de dizer não dizendo sim, afirmando a própria dominação e seu contrário, enuncianto e criando visíveis antagonismos não resolvidos, sujeiçōes, violências.

Analisando as práticas dos movimentos, a ciência social encontra formas de reprodução das relações de dominação ali mesmo onde elas estão sendo questionadas. Pois, se a resistência é contrapoder, se dá no campo delineado por ele. Nesse sentido, cultura de resistência trała de um conflito desigual no qual se pode vislumbrar o poder dos dominados enquanto tais. Resistência é re-ação. Como poderia deixar de ser modelada pelas próprias injunções da dominação? Como poderia a resistência não se definir pela negatividade, pelo que nela não se conforma, mas se autodefine por essa negação? $O$ tema remete a uma identidade que é negativa porque se define na experiência da discriminação. A ambigüidade está, pois, no centro da discussão (e das experiências que a expressão pretende delimitar, nomear e qualificar), estejam em jogo os modos de vida das classes populares ou das mulheres que amam mulheres.

A consideraçăo do social como antagonismo no sentido indicado remodela também o modo de conceber os sujeitos e de caracterizar os conflitos. Tratando do assunto, Emesto Laclau constrói dois modelos: o primeiro corresponde ao modo como o século XIX concebeu e constituiu historicamente os sujeitos e os conflitos políticos; o segundo refere-se às concepções e práticas políticas próprias às sociedades modemas contemporâneas. Descrevo-os rapidamente aqui porque, exatamente por serem modelos, expõem organizadamente os aspectos que quero discutir. Mas como ficará claro a seguir, a classificação histórica dos modelos está longe de ser adequada para a discussão que se segue.

No primeiro modelo, o sujeito aparece como unidade racional e transparente, na qual um núcleo fornecedor de sentido funciona como fonte da açảo, confe-

3. M. Foucaul, Microfisica do Poder, Rio de Janeiro, Graal, 1982. 
rindo significado homogêneo para o campo total da experiência do indivíduo. É claro que a referência aqui é a posição do indivíduo na esfera das relações de produção, que funcionaria como o núcleo gerador da identidade. A esse modo de pensar o sujeito corresponde um modo de conceber o antagonismo, por meio da lógica da equivalência e da diferença, que divide a totalìdade social em dois grandes campos opostos. A identidade de um dos campos se constrói negando o outro, sendo que cada um deles se compõe de uma cadeia de equivalências. Em outras palavras, trata-se da construção de um nós e de um eles, dois campos totalmente antagônicos, de modo que se está em um ou no outro: ou você está conosco ou está contra nós. E, entre nós, todos se equivalem e se identificam com um imaginário político unificado, isto é, com um conjunto de signifícados que operam como horizonte do movimento, que projeta como realização de si a construção de uma nova ordem total, em tudo oposta àqquela identificada com os valores do campo adversário. Ou seja, um horizonte que projeta o momento de totalização da identidade do grupo, isto é, de generalização social a partir de uma identidade particular. Os conftitos entre o povoe o Antigo Regime na época da Revolução Francesa e, mais tarde, entre o proletariado e a burguesia seriam exemplos típicos dessa forma de conflito e de constituiçăo de sujeitos coletivos.

O segundo modelo conforma-se a partir de experiências políticas próprias ao século XX, e especialmente a partir da reflexão sobre os movimentos sociais. Nele concebe-se o sujeito como descentralizado e destotalizado, uma construção contínua, dinâmica e instável, um complexo indeterminado feito de várias posições. Desse modo, o agente é concebido como pluralidade, dependente de várias posições de sujeito, a cada uma das quais correspondem diferentes formações discursivas, em cujo âmbito o indivíduo é constituído. Esse indivíduo que se posiciona de modo variado em momentos e lugares específicos de sua vida - por exemplo, mulher, trabalbadora assalariada, mãe, católica, homoeroticamente orientada, branca - fornece uma imagem fragmentada, feita de parcialidades, descentralizada e indeterminada. Por certo Laclau contempla a possibilidade de articulação entre diferentes formações discursivas que formariam então o que ele chama de discurso. O ponto a destacar é que as articulações são conexões históricas e variáveis, indeterminadas e contingentes, cuja possibilidade reside no caráter radicalmente ambíguo dos temas presentes nas diferentes formações discursivas, relativos às diversas identidades fragmentadas dos sujeitos sociais. Portanto, mesmo quando articulam diversas dimensões da experiência, as identidades não têm um núcleo, năo são determinadas nem necessárias. Os sentidos políticos das identidades que assim se constituem são, como as articulações que os constroem, indeterminados e contingentes. 
Esses sujeitos descentrados que Laclau vê nos movimentos sociais configuram um outro tipo de conflito.

Os antagonismos proliferam, politizando áreas específicas das relações sociais, criando seu próprio espaço diretamente politizado. Isto quer dizer que não apontam para a politização em uma outra área, na qual os interesses da primeira fossem representados. Desse modo, o espaço político deixa de ser um nível preciso e unificado do social (o nível da representação de interesses) para tornar-se uma dimensão do rea1, passível de manifestar-se em sua multiplicidade, na variedade das relações sociais. Conseqüentemente, o imaginário político dos movimentos não projeta um novo modelo total de sociedade a ser instaurado, no que Laclau localiza o potencial radicalmente democrático dos movimentos sociais. Politizando o presente e o específico e revelando cada arranjo global como resultado contingente de práticas discursivas articulatórias, os movimentos contemporâneos superariam o "absolutismo do Iluminismo" que sustentou o desejo da modernidade de dominar o fundamento do social, fornecendo um contexto racional para a totalidade da história para nele basear um projeto total de emancipação. ${ }^{4}$

Tendo retirado o fundamento do sujeito e da identidade e afirmado seu caráter radicalmente aberto e contingente, a teoria social depara-se com as seguintes perguntas: qual o sentido político das experiências historicamente em constituiçăo pela ação dos sujeitos sociais no campo dos debates político-culturais contemporâneos? Se sua ambigüidade determina que seus sentidos não se definem a priori, mas se constroem em práticas concretas, então, para onde apontam estas práticas? Para a emancipação humana e ampliação das liberdades ou, ao contrário, para a manutenção da dominação e o fortalecimento do direito do mais forte, da intolerância, da indiferença?

A ambigüidade está no cerne do mundo contemporâneo, quer dizer, ela está no cerne do pensamento contemporâneo do mundo. A ambigüidade do objeto de reflexão está igualmente na própria reflexão, de tal modo que as possibilidades do pensamento na atualidade são aquelas do movimento do pêndulo: diante da percepção da ambigüidade, visível para nós praticamente em todo fenômeno social, é possível enfatizar um lado ou outro, dependendo da escolha daquele que analisa. Exploram-se as ambigüidades, mas sempre se pende para um lado ou outro, positivo ou negativo, ou seja, libertário ou regressivo. Quanto a isto, o debate contemporâneo parece seguir um padrão que é a expressão de nítidos e angustiantes limites: questionamos aquele que enfatiza a positividade,

4. E. Laclau, "Os Novos Movimentos Sociais e a Pluralidade do Social", Revista Brasileira de Ciências Sociats, vol. 1, $n^{0}$ 2, outubro de 1986, pp. 41-7. 
mostrando os aspectos regressivos; e diante daquele que expõe preferencialmente a negatividade, chamamos a atenção para os sentidos alternativos $\mathrm{e}$ criativos. Conforme o contexto e o interlocutor, o pensamento se move para um pólo ou para o outro.

O quadro, que já é bastante problemático, complexifica-se ainda mais no âmbito dos debates sobre identidades étnicas, de gênero e de orientação sexual. Primeiro, quando aqueles que foram concebidos como os portadores de uma perspectiva social aberta, radicalmente múltipla, reatualizam uma concepção fixa, natural e totalizante de si mesmos. Segundo, quando os discursos desses agentes são apropriados por outros com um sentido contrário, criando o paradoxo que o neo-racismo corporifica em sua forma mais bem-acabada e surpreendente, com sua defesa da discriminação e da segregação em nome da autenticidade das culturas.

Quando certas vertentes dos movimentos projetam a construção de uma identidade coletiva homogênea a partir de um ponto nuclear - núcleo que varia segundo o grupo, podendo localizar-se na condição de ser negro, mulher ou homossexual -, repõe-se uma concepção do sujeito baseada na idéia da identidade homogênea, coerente e possuidora de um fundamento. Nos casos citados, trata-se de fundamentos apresentados como naturais, biológicos ou fisiológicos, de modo que, surpreendentemente, recoloca-se no centro do debate uma concepção naturalizada da culıura, na contracorrente de toda a reflexão antropológica moderna que se distingue por conceber a cultura como criação arbitrária e, portanto, por rejeitar totalmente uma concepção da identidade como fenômeno de base natural.

A perspectiva que se abre com a noção de uma identidade naturalmente fundamentada vem conquistando espaço no campo dos debates contemporâneos, orientando, inclusive, pesquisas recentes que buscam identificar e medir os supostos fundamentos naturais das condutas humanas, de modo que estamos às voltas com uma discussão (na qual não sei se o mais surpreendente é sua imensa repercussão social ou a imensa falta de fundamentação científica dos trabalhos) sobre QI de negros, genes de homossexuais e determinações biológicas do comportamento masculino e feminino, o que quer que isso queira dizer.

Como se viu na exposição do Modelo 1 de Ernesto Laclau, uma concepção totalizante do sujeito liga-se a um modo de constituição do conflito social que desenha dois grandes campos totalmente antagônicos, conforme uma concepçăo hierárquica que não admite dois primeiros lugares, para usar a expressão de Jurandir Freire Costa. ${ }^{5}$ A forma do conflito que, segundo Laclau, caracte-

5. J. F. Costih A hocência e o Vicio: Estudos sobre o Homoerotismo, Rio de Janeiro, Reiume-Dumará, 1992. 
rizaria o século XIX se reatualiza nos antagonismos sociais do final do século $\mathrm{XX}$ de um modo especialmente antimoderno, já que os novos núcleos da identidade não remetem mais a relações sociais, mas a realidades fisiológicas, criando sérias dificuldades para a idéia da negociação democrática entre perspectivas diferentes, que teria por base comum o reconhecimento da pluralidade. Ao contrário, ela projeta a negação total de um adversário muito bem delimitado, destruindo, no limite, a própria idéia da diferença, na medida em que diversas particularidades se apresentam como as legítimas detentoras de uma nova universalidade, finalmente verdadeira, finalmente fundamentada em bases sólidas, nada menos que nas leis da evolução da espécie, nas cadeias de DNA ou nas estruturas simbólicas universais da psique humana.

Desse modo, deparamo-nos com fortes argumentos para a interpretação da lógica inerente à idéia da particularidade como necessariamente regressiva. Diante da concepção de particularidade fundamental, a concepção pluralista do mundo e a defesa do direito à diferença parecem não atuar no sentido da ampliação dos valores democráticos mas, ao contrário, funcionam como justificativas para novas formulações dos valores da discriminação e da segregação.

\section{A intimidade como tirania}

Esses desdobramentos recentes do debate em torno das identidades étnicas e sexuais têm favorccido uma resposta negativa à pergunta sobre os sentidos políticos historicamente em constituição nas práticas dos movimentos de identidade, resposta presente de diversas formas na discussão atual, basicamente em torno do mesmo tipo de argumento, mas com perspectivas bastante variáveis. A interpretação de um sentido político regressivo dos movimentos de identidade parece, assim, tendencialmente predominante. Uma de suas formulações mais convincentes é a de Richard Sennett, em seu livro publicado na sua versão original em 1974, O Declínio do Homem Público: As Tiranias da Intimidade. ${ }^{6}$ Nele, Sennett apresenta uma análise devastadora da perversão da fraternidade na experiência moderna de comunidade. Para o autor, a modernidade contemporânea constitui-se como sociedade intimista, voltada para a busca de uma identidade interior e afetiva que substitui a ação pelo sentimento. Recusando os vínculos de associação e de compromisso entre estranhos,

6. R. Sennett, O Declínio do Homem Público: As Tiranias da Intimidade, Sảo Puulo, Companhia das Letras, 1988. 
característicos da vida pública, considerados formais e falsos, os indivíduos modernos crêem que significações sociais são geradas pelos sentimentos pessoais. Por isso, buscam na vida privada a vivência autêntica dos sentimentos, mediante a qual teriam acesso à autenticidade de si: "o eu de cada pessoa tornou-se o seu próprio fardo; conhecer-se a si mesmo tornou-se antes uma finalidade do que um meio através do qual se conhece o mundo". ${ }^{\prime}$

A passagem da idéia da representação como modo de ação social para a idéia da expressão sincera de si é exemplificada pela redefinição do amor físico dos termos do erotismo para os da sexualidade:

\footnotetext{
"[...] o erotismo vitoriano envolvia relacionamentos sociais, enquanto a sexualidade envolve a identidade pessoal. $O$ erotismo significava que a expressão sexual transpirava por meio de açỏes - de cscolha, repressāo, interaçāo. A sexualidade năo é uma ação, mas um estado no qual o ato físico do amor decorre quase como uma conseqüência passiva, como um resultado natural do sentimento de intimidade entre duas pessoas. [...] Amplos segmentos da sociedade moderna têm se rebelado contra o medo e a repressão. Mas devido ao modo pelo qual os ideais de intimidade avivam a imaginação moderna, tem também havido reação contra a idéia de que o amor lísico é uma ação [social]". ${ }^{8}$
}

O amor físico torna-se uma revelação do eu: dize-me o teu desejo e eu te direi quem és. Trata-se de um dos modos de buscar "uma identidade composta por materiais vindos de dentro"."

No plano individual, a imaginação psicológica da vida inibe o desenvolvimento de forças básicas da personalidade, libera forças destrutivas e condenanos à insatisfação, pois, sempre segundo Sennett, "quanto mais privatizada a psique, menos estimulada ela é e tanto mais difícil será sentir ou exprimir sentimentos". ${ }^{10}$ No plano coletivo, o problema é que tratamos a vida pública segundo os critérios da vida privada, ou seja, tratamos os assuntos públicos em termos de sentimentos pessoais, como se fossem questões de personalidade, as únicas capazes de suscitar paixão.

Superposto ao imaginário público, o imaginário privado moderno vai modelar uma atuação de tipo comunitário, fundada sobre identidades íntimas e pessoais: "a obsessão para com pessoas, em detrimento das relações sociais mais impessoais [...] leva-nos a crer que a comunidade é um ato de desvendamento mútuo e a subestimar as relações comunitárias de estranhos". ${ }^{11}$ Organizados em comunidades afetivas, os sujeitos políticos modernos atuariam

7. Idem, p. 16.

8. Idem, p. 20.

9. Idem, p. 23

10. Idem, p. 16

11. ldem, p. 17. 
segundo uma lógica que tende a desenhar uma fronteira rígida entre um nós e um eles, baseada na percepção de um ultraje, de uma dignidade ofendida que impede qualquer negociação. $O$ desdobramento desse modo de constituir a identidade aponta mais para um desejo de defesa local contra o mundo, inspirador de sentimentos do tipo "deixem-nos em paz", do que para uma vontade de mudar o mundo, de desafiá-lo. Isso se dá mediante a transformação da ação política, que é um jogo, em uma verdade íntima para os indivíduos modernos, obcecados pela autenticidade da identidade:

\footnotetext{
"[...] quando um grupo de pessoas se reúne com propósitos políticos, forja algumas posturas comuns para clas próprias, e então começam a se comportar com base nessa aparência comum; gradati vamente, elas começam a acreditar nela, a aderir a cla, a defender a postura por cla mesma. Ela se encaminha para tomar-se uma definição real de quem sāo elas, mais do que uma posiçāo adotada durante um jogo pelo poder".'2
}

Os termos culturais da personalidade apoderam-se do grupo, levando-o a pensar a si mesmo como coletividade emocional. Nesse ponto, "a face que se volta para o mundo exterior se torna rígida, e a comunidade se engaja numa corrida interna que se torna cada vez mais destrutiva". ${ }^{13}$ Essa corrida se refere aos processos de fragmentação e depuração que atingem o grupo - a experiência de compartilhar de uma revolta e de um modo de ser torna-se uma espécie de comunhão, e aqueles que não compartilham dos sentimentos comunitários se tornam suspeitos dentro do próprio grupo. Como, por exemplo, no movimento negro americano no qual "cada uma das diferentes facções envolvidas em disputas táticas e planos de Iongo alcance gradativamente passou a ver a si mesma como a única voz legítima 'da gente' (the people). Forasteiros, outros negros, não menos do que brancos, deviam ficar de fora" ${ }^{14}$

Para Sennett, a intimidade moderna é uma forma de tirania baseada na crença em "um padrão de verdade para medir as complexidades da realidade social. $\hat{E}$ a maneira de se enfrentar a sociedade em termos psicológicos", 15 concebendo-a como realidade emocional. Com isso, "a comunidade se torna uma arma contra a sociedade, cujo maior defeito é tido como sendo sua impessoalidade". ${ }^{16}$ Ora, segundo o autor,

"[...] uma comunidade de poder só pode existir como uma ilusão numa sociedade como a do Ocidente industrial, na qual a estabilidade se completou por uma extensāo progressiva
12. Idem, p. 371 .
13. Idem, ibidem,
14. Idem, p. 376.
15. Idem, p. 412.
16. Idem, p. 413 . 
da escala intemacional de estruturas de controle cconômico. Em suma, a crença nas relaçōes humanas diretas em escala intimista nos seduz c nos desvia da conversão de nossa compreensão das realidades do poder em guias para nosso próprio comportamento político. O resultado disso é que as lorças de dominaçăo ou a iniquüidade permanecem inatacadas". ${ }^{17}$

Penso que Sennett expõe vários dos calcanhares de Aquiles dos movimentos de identidade. Para ele, o retrocesso moderno da civilidade libera forças que impedem a auto-realização do indivíduo, de modo que estamos profundamente insatisfeitos com essa interminável busca do $e u$ verdadeiro e autêntico que, se levarmos em conta o gesto das pessoas quando falam dele, levando a mão trêmula pela intensidade do gesto ao peito, deve localizar-se em alguma parte entre o coração e o umbigo. Precisamos aprender a rir um pouco de nós mesmos em nossa incansável busca do "meu etr", neste mundo altamente psicologizado, cheio de emoções e sentimentos, com sua forte tendência ao que há de mais piegas nas nossas representaçôes do amor, da intimidade, da felicidade. Por certo, trata-se de uma questão especialmente importante para as mulheres em geral e para aquelas homoeroticamente orientadas, dado o lugar central que o sentimento e a intimidade ocupam nos discursos de identidade feminista e lésbica. $^{18}$

Outra questão importante refere-se à lógica interna de fragmentação e depuração dos grupos comunitários. Na história do grupo homossexual Somos, reconstituída por Edward MacRae em A Construção da Igualdade, é possível observar a força dessa tendência de contínua divisão interna, por meio da qual, aliás, constituem-se as primeiras organizaçôes lésbicas no Brasil. O trabalho de MacRae descreve com detalhes os conflitos pessoais, as alianças afetivas, as lutas em torno da đelimitação das especificidades, as práticas de desqualificação dos opositores, as dificuldades de comunicação e mobilização. ${ }^{19}$ A tendência não tem nada de específica, marcando a experiência dos mais diversos movimentos de identidade, e também não caracteriza um período inicial ou de crise da organização. Ao contrário, as lutas internas pelos pequenos poderes configuram um dos mais sérios problemas nos movimentos, ${ }^{20}$ levando muitas pessoas a abandoná-los, desiludidas. De acordo com a leitura de Sennett, os problemas resultam da própria lógica de organização da identidade e signifi-

17. Idem, p. 414.

18. Cf. R. Osborne, "Lesbianismo e Feninismo", Nosotras que Nos Queremos Tanto..., Colectivo de Feministas Lesbianas de Madrid, $n^{\circ} 6$, fevereiro de 1988.

19. E. MacRae, A Construçāo da Igualdade: Identidade Sexual e Politica no Brasil da "Abertura", Campinas, S.P., Ed. da Unicamp, 1990

20. Coletivo de Feministas Lésbicas, Lésbicas no Brasil. Contribuiçāo para Avaliaçäo da Década da Muther, 1985-1995, São Paulo, julho de 1994. 
carn, em suma, que, pensando estar enfrentando o preconceito em nome da emancipação, estamos de fato destruindo as possibilidades de realização pessoal e de constituição de uma vida coletiva regida democraticamente.

\section{Movendo o pêndulo: política e eficácia}

Embora a leitura de Sennett me convença profundamente das tiranias da vida social intimista, com as quais me deparo cotidianamente, é preciso reconhecer que, da perspectiva dos movimentos, tal interpretação é paralisante. E o problema é que não consigo negar as conquistas dos movimentos de gênero $\mathrm{c}$ de orientação sexual nos últimos tempos. Alguém ousaria negar as mudanças recentes nos modos de a sociedade moderna, incluindo a sociedade brasileira, tratar tanto a questăo das mulheres como da homossexualidade? Mesmo considerando todos os problemas envolvidos, eu não gostaria de voltar atrás, a um tempo, bastante próximo, quando não havia nenhum discurso disponível para ao menos tentar enfrentar os desmandos do preconceito e da intolerância. Nesse ponto, a ambigüidade distintiva do pensamento contemporâneo revela alguma potencialidade. Movimentando-me no pêndulo e, sem querer descartar a análise de Sennett, quero considerar o problema da perspectiva da pergunta que ela deixa no ar: o que fazer?

O ponto a destacar é que os discursos de identidade são eficazes no campo político, tal como ele está constituído. Eficazes para dentro e para fora. Aqueles que atuam nos movimentos conhecem a eficácia dos discursos da intimidade, da revelação de si, da representação de uma identidade partilhada. Sabemos muito bem que não há workshop sobre sexualidade, gênero ou homossexualidade que não passe por umas boas rodadas de revelações públicas de desejos, frustrações e toda sorte de experiências íntimas e pessoais. Ora, é isso mesmo que engaja as pessoas na discussão. Do mesmo modo, a divulgação de significados alternativos aos impostos pelos padrões dominantes tende a apelar para o tal "eu profundo" das pessoas, naquele movimento característico de produzir orgulho e auto-estima no lugar da vergonha que a sociedade imputa aos seus marginalizados. No mesmo sentido, a idéia de que a orientação sexual resulta de um impulso interno irresistível é a que mais encontra ressonância entre setores sociais mais amplos, conforme a opinião de pessoas que têm levado a discussão aos espaços políticos convencionais. ${ }^{21}$

21. Cf. comentários de M. Suplicy e E. Blay, Femme. Revista Lésbica Brasileira, Grupos Afins, ano II, $\mathrm{n}^{\circ}$ 5, setembro de 1994, pp. 33-5. 
A questão é: como poderia ser de outro modo? Como podem os movimentos de identidade fugir a uma lógica para a qual certamente contribuem, mas que é também muito maior do que eles? Sabemos que a política moderna se define pela busca da eficácia. A política é eficaz quando consegue mobilizar a vontade. Para isso, ela deve falar a linguagem daqueles para os quais se dirige, se quer ser entendida e se quer conquistar adesão. Trata-se de uma lógica perversa e, pode-se dizer, fundamentalmente demagógica e manìpulatória. A solução, então, seria abandonar tudo? Como é possível reorientar o existente, partindo, necessariamente, dele?

Assim, o ponto central de minha reflexão localiza-se num dilema. Por um lado, a reflexão sobre as questões da identidade, do sujeito, da cultura e da dominação encaminha-se distintivamente para a ambigüidade. Por outro, na esfera da constituição de sujeitos coletivos capazes de se mobilizar para a defesa de certos valores, ou seja, no espaço da ação política, tudo parece indicar que a eficácia dessa ação depende da capacidade de se construir concepções positivas de identidade, de cultura e de sujeito. Tudo se passa como se na hora da reflexăo tratássemos de desconstruir, contanto que na hora da ação seja possivel afirmar, obviamente para poder negar o outro com a veemência exigida pela situação de conflito e enfrentamento.

A Sociologia, a Antropologia e a Psicanálise ensinam que o sujeito é descentrado e fragmentado e que quando articula alguns de seus fragmentos, trata-se de uma operação contingente, instável e não necessária, absolutamente contextual. Mas quando olho para a dimensão política, isto é, quando imagino minha reação diante de uma fala machista, preconceituosa e investida socialmente de poder de modo a me ameaçar, não vejo outra possibilidade lógica senão desconstruir o discurso do outro, afirmando veementemente a positividade do lado de cá, de um eu (ou um nós) defínido, positivo e total. No jogo entre nós e eles, só há positividade total e negatividade total. Portanto, intolerância. Há uma dificuldađe lógica em pensar a possibilidade da tolerância com o inimigo definido pela intolerância. A política contemporânea, difusa no social, ainda constitui um campo raivoso.

O problema configura-se claramente nesses termos na discussão de MacRae sobre as críticas de Peter Fry e Jean Claude Bernardet às diretrizes do Somos quanto ao modo de conceber a identidade homossexual. Ele observa que

"[...] é necessário reconhecer que dentro do Somos, a despeito das várias mudanças no plano teórico, en termos práticos c efetivos predominava uma atitude de afirmação homossexual [, isto é, de] constante reiteração pública ou privada dessa orientaçāo sexual e tentativa de mobiljzaçầo em defesa daqueles identificados como homossexuais no tocante ao respeito aos seus dircitos de cidadania. [Segundo MacRac,] a utilidade dessa 
posiçāo num processo de mobilizaçāo política é clara. [Tanto que] durante o auge do movimento homossexual no Brasil talvez se pudesse dizer que a idéia de uma 'essência homossexual' também foi muito importante para a aglutinação de pessoas dispostas a levantar a questāo. Posiçōes que poderíamos chamar de 'resistência criativa', cono as propostas por Fry e Bernadet, seriam apropriadas a uma segunda fase que se seguiria à consolidação de conquistas no terreno dos direitos civis. Sintomaticamente seus artigos foram publicados em 1982, já aproveitando um espaço que talvez não cstivessc tāo abcrto a esse tipo de discussão se não fosse por toda a militância desenvolvida pelos grupos homossexuais nos anos anteriores". ${ }^{22}$

Penso que atualmente o problema remete menos a uma questão cronológica, de primeiro e segundo momentos, e mais à questão da simultaneidade de espaços distintos, com lógicas autônomas. A identidade é uma "ficção necessária", para usar a expressão de Boaventura Santos. ${ }^{2 .}$ Pois bem, quando no espaço da reflexão, concentro-me sobre seu caráter ficcional, portanto, desconstruo-a. Mas quando no espaço da política, concentro-me na sua necessidade, portanto, direciono todas as encrgias para construí-la. Ei-nos profundamente mergulhados no dìlema resultante da própria fragmentação da experiência moderna que se ordena conforme uma lógica ou outra, dependendo da posição de sujeito em que se coloca. Como rearticular essas posições de outra maneira de modo que o arranjo possua potencialidade emancipatória? É o momento em que o pensamento político, sem jogar fora a perspectiva da eficácia da açăo, tem de vislumbrar a possibilidade da criação.

\section{A intimidade como democracia}

Entendo que é isso que Anthony Giddens faz quando inventa um outro sentido para a transformação da intimidade nas sociedades modernas, reorientando a leitura das experiências contemporâneas do amor, do sexo e do erotismo para apresentar a emancipação sexual não como "um conjunto substantivo de qualidades psíquicas ou formas de comportamento", mas como uma "forma de ação, como a possibilidade da democratização radical da vida pessoal". ${ }^{24}$ Note-se que se trata justamente de repor a ação no espaço da sexualidade e das relaçōes pessoais, de modo a redirecionar o sentido das projeçōes dos valores

22. E. MacRac. A Construçäo da Igualdade... op. cit., pp. 59.60 e 62.

23. B. de Solza Suntos, "Modernidade, Identidade e Cultura de Fronteira", Tempo Social, vol. $5, n^{\circ} \mathrm{s}$ 1-2, novenbro de 1994.

24. A. Giddens, A Tramsfomaçáo da Intimidade: Sexualidade. Amor e Erotismo nas Sociedades Modemas. Sāo Paulo, Editora da Universidade Estadual Paulista, 1993, p. 200. 
da vida privada sobre a vida pública: de um sentido regressivo, como em Sennett, para um sentido emancipatório.

Para Giddens, a democratização da vida pessoal, na qual as mulheres desempenham o papel principal, refere-se à emancipação implícita no relacionamento puro, baseado em uma sexualidade plástica, tornada possível pela liberação das necessidades de reprodução, ou seja, de imperativos de ordem natural. A sexualidade, em vez de ficar aprisionada no interior de uma busca de auto-identidade, projeta uma política de vida capaz de remoralizar as decisões relativas aos estilos de vida. Embora reconheça que a intimidade moderna pode ser opressiva, Giddens propõe uma utopia: a definição da intimidade como um conjunto de direitos e deveres, um "aglomerado de prerrogativas e responsabilidades que definem os planejamentos da atividade prática". ${ }^{25}$ Nesse contexto, a revelaçăo de si para o outro, por cxcmplo, deixa de ser esvaziamento emocional para funcionar como meio de comunicação e de transformação da moralidade. Se considerada como uma negociação transacional de vínculos pessoais, estabelecida por iguais, a intimidade surge sob uma nova luz: implica a democratização do domínio interpessoal e pode exercer urna influência subversiva sobre as instituições econômicas e políticas modernas.

Uma simetria entre a democratização da vida pessoal e as possibilidades democráticas da vida pública pode orientar uma negociação que se baseie em princípios e não na "troca de posições". Em Giddens, a troca de posiçôes define aquele tipo de enfrentamento que constitui dois campos totalmente antagônicos, ou seja, quando cada lado se aproxima da negociação assumindo uma posição extrema e, por ameaças mútuas e atritos, chega a um resultado, isto se a negociação já não tiver se desintegrado. Concebendo uma negociação conforme princípios, a diferença, que impede o entendimento mútuo, pode tornar-se meio de comunicação.

Comparada com a leitura de Sennett, a interpretaçăo de Głddens parece pouco fundamentada e nada realista. Mas a sua fraqueza analítica é o outro lado da sua ousadia política de enunciar um sentido diferente para a intimidade moderna, tentando rearticular sua perspectiva política tanto no âmbito das relações pessoais quanto no plano político-social global. Alterando as definjções, ele tenta ampliar o horizonte da temática das identidades sexuais, projetando um sentido pessoal e coletivo emancipatório para as experiências contemporâneas da intimidade.

25. ldem, p. 208. 


\section{Comentário final}

A leitura de Giddens aponta para uma ampliação das perspectivas dos movimentos de identidade, na direção oposta aos fracionamentos próprios às concepções de especificidade irredutíveis entre si. Penso que essa diretriz, certamente utópica, pode, entretanto, ser adequada para o momento atual, quando o principal adversário visível em torno do qual os movimentos de identidade sexual se rearticulam é a ADDS. Em certo sentido, a luta contra a AIDS aponta para uma perspectiva ampla, menos de fracionamentos do que de alianças, pois estamos todos - muitos e diferentes - no mesmo barco. Por um lado, a luta contra a AIDS tende a expandir nossa visăo dos poderes sociais de discriminaçăo e dominaçăo. Denunciando o preconceito, o desrespeito e a indiferença, os discursos contemporâneos revelam as perversidades de que é capaz a sociedade modema, seus governos, seus cidadãos, suas empresas e suas instituições. Por outro lado, a gravidade do problema abre mais espaços para a abordagem das questões de orientação sexual. Dada a própria história do advento da AIDS, sua discussão incorpora o tema da discriminação por orientação sexual, articulando-o com questões relativas à lógica do poder econômico e das desigualdades de classe e com uma contradição básica da modernidade contemporânea que, ao desrespeitar o direito à vida, fere o valor básico sobre o qual ela se afirmou como sociedade secular, livre e igualitária.

Convenhamos que o direito à diferença se constitui como um privilégio de setores sociais bem delimitados. Um problema especialmente sério para a sociedade brasileira, que não cansa de aumentar suas desigualdades sociais, de modo que também a identidade aqui se constitui como privilégio de alguns. Talvez, o terrível surgimento da AIDS possa atuar também como o adversário que nos reaglutina, abrindo espaço social para uma resignificação da experiência discriminada e, assim, da defesa da pluralidade. Não é uma necessidade que a luta pelo direito à diferença pressuponha a identidade; ela pode pressupor a igualdade, propondo-se a explorar a ambigüidade central da modernidade que, para se impor, inventou um valor capaz de forçar seus próprios limites.

\section{RESUMO}

\section{A Propósito de Sexualidades e Culturas de Resistência: Modernidade, Identidade e Política}

Neste texto, säo explorados dilemas do debate político-cultural contemporâneo, em especial a questăo dos sentidos políticos dos processos de formação de 
identidades dos movimentos sociais. Para tanto, discute-se a tensão entre a leitura que desvenda um sentido tirânico, e portanto regressivo, nos movimeñtos de identidade parciais e a interpretação que revela as potencialidades democráticas, e portanto emancipatórias, desses mesmos movimentos, em termos pessoais e coletivos. Essa tensão remete, finalmente, ao problema, fundamental do ponto de vista dos próprios movimentos, das diferenças entre a lógica crítica e a lógica da ação política na sociedade contemporânea.

\section{ABSTRACT}

\section{On Sexualities and Resistence Cultures: Modernity, Identity, and Politics}

The problems of the contemporary political and cultural debate, especially the issue of the political meanings of the social moviments identities formation process are discussed in this text. In order to do that, on discuss the tension between the knowledge that reveals an arbitrary sense, therefore regressive, in the partial identity moviments, and the interpretation that reveals the democratic potentialities, therefore emancipatory, of these moviments, on personnal and colective terms. Finally, this tension aludes to the problem, important on the point of view of the moviments themselves, of the differences between the critical logic and the political action logic in the contemporary society.

\section{RÉSUMÉ}

\section{À Propos de Sexualités et Cultures de Resistance: Modernité, Identité et Politique.}

Les dilemmes du debat politico-culturel contemporain, spécialement la question sur les sens politiques des procédés de formation d'identités des mouvements sociaux sont exploités dans ce texte. Pour cette raison, la tension entre la lecture qui devoile un sens tyranique, et donc regressif, dans les mouvements d'identités partielles et l'interprétation qui révèle les potentialités démocratiques, et donc emancipés, de ces mêmes mouvements, en termes personnels et collectifs sont mis en question. Cette tension remet, finalement, au problème, essentiel du point de vue des propres mouvements, des differences entre la logique critique et la logique d'action politique dans la société contemporaine. 